\title{
Nutritional Quality of Eggs of Amberlink and Hyline Layers Fed on Different Levels of Provitamin A-Biofortified Maize
}

\section{-Author(s)}

\section{Zeina GW'}

Kolanisi $U^{\prime}$

Chimonyo $\mathrm{M}^{\prime \prime}$

Department of Consumer Sciences, University of Zululand, Faculty of Science and Agriculture, Private Bag X1001, KwaDlangezwa, 3886, South Africa

" School of Agricultural, Earth \& Environmental Sciences, College of Agriculture, Engineering and Science, University of KwaZulu-Natal, Private Bag X01, Scottsville, 3209, South Africa

\section{ABSTRACT}

The study was conducted to determine the interaction of types of maize (Provitamin A-biofortified maize (PABM) versus white maize) and strain of laying birds (Amberlink and Hyline) on nutritional quality of eggs. Twenty-one of each of Amberlink and Hyline laying hens were fed on three diets for 30 days. Birds were distributed in a $3 \times 2$ factorial arrangement constituting three diets $(0,50$ or $100 \%$ of PABM) and two strains (Amberlink \& Hyline). There was a diet $\times$ strain interaction on egg shell weight, average daily feed intake, egg production, egg weight and egg shell thickness. Eggs produced by layers under $100 \%$ PABM had lighter eggshell weight and lower eggshell percentage. In contrast, eggs produced by layers under $50 \%$ PABM diet had significantly higher eggshell percentage, heavier egg shell weight and thicker eggshell. As the level of PABM increased, the yellow and red hue (Hunter $a^{*}$ and $b^{*}$ values) significantly increased while the lightness values (Hunter $L^{*}$ values) decreased. As the level of PABM in the ration increased, the vitamin A content of the egg yolk also significantly increased. Assimilation of vitamin A from feed to egg yolk in Amberlink and Hyline hens was similar. Hence, egg enrichment with vitamin A can be achieved by using PABM in layers ration. The use of high level of PABM had a negative effect on the eggshell quality traits.

\section{INTRODUCTION}

Chicken eggs are one of nature's most wholesome foods. Egg yolk contains natural carotenoids, and it's yellow colour is attributed to the presence of $\beta$-carotene, zeaxanthin, kryptoxanthin and lutein naturally found in commercial feed. The internal and external quality of eggs varies due to heredity, diet and age of the hen. Vitamin concentration of eggs is also influenced by the level of vitamins in the diet (Naber \& Squires, 1993).

Because of the health benefits of vitamin $A$ to humans, biofortification of maize with provitamin $A$ has been promoted to curb vitamin A deficiency (VAD) among children, pregnant women and the elderly (Pillay et al., 2013). Assessment of vitamin A content is rare, partly because of the high cost of laboratory assays and the overreliance on crude protein as the major limiting nutrient for resourcepoor households. The "hidden hunger" that is caused by deficiency of micronutrients has not yet received adequate attention. Consumers from many African communities do not prefer the use of yellow maize, hindering the use of provitamin A biofortified maize (PABM) to combat VAD (Stevens, 2008). To curb this predicament, PABM could be used to enhance the vitamin A content of eggs (Liu et al., 2012). Although biofortification of maize has a huge potential to curb VAD (Pillay et al., 2013), the response of different strains in converting $\beta$-carotene to vitamin $A$ is not clear. It has been suggested that the extent of 
utilization of PABM could interact with strains of birds. It is possible that fast growing strains could assimilate less of dietary nutrients, including vitamins, into eggs than slow-growing chickens. The consequences on physical egg characteristics are also unknown. It is generally understood that improvement in one trait should consider the effect it will have on other desirable characteristics. Given that PABM have superior level of starch and crude protein as compared to white maize, it is important to assess its effect on the egg quality traits (Pillay et al., 2013). To date, there is no information on how the PABM affects the performance of egg laying birds. It is also unclear whether bird strains respond differently when fed on PABM.

Amberlink chickens are a cross between the Rhode Island Red and Rhode Island White. The Hyline is a prolific egg layer, bigger than the Amberlink. Both Hyline and Amberlink chicken are hybrid strains that are popular for their high egg production, livability and efficiency of feed utilization (Hy-Line W-36, 2009; Institut de Sélection Animale, 2014).

The objective of the study was to determine whether level of PABM inclusion in feed affects the quality of eggs produced from Amberlink and Hyline hens. It was hypothesized that there is an interaction between PABM inclusion and strain of bird in egg quality and vitamin A concentration.

\section{MATERIALS AND METHODS}

\section{Facilities and management}

The experiment was conducted at the Ukulinga Research Farm, University of KwaZulu-Natal. All procedures used in the experiment were approved by the Animal Ethics Committee of University of KwaZuluNatal (Reference: 088/14/Animal). The experiment was conducted on twenty one of each of Amberlink and Hylinelayers. The point-of-lay Amberlink and Hyline birds were obtained from Inverness Rearers (Pty) Ltd (Mooi River), Midlands, KwaZulu-Natal. The birds were evaluated upon receipt for signs of diseases such as Newcastle disease, fowl typhoid and fowl pox. Each bird was individually assigned to a metal cage equipped with trough feeders and nipple drinkers. At the start of the experiment, all birds were 30 weeks old with a mean body weight of $1.79 \pm 0.108$ and $1.93 \pm$ $0.103 \mathrm{~kg}$ for Amberlink and Hyline birds, respectively. A 17-h photoperiod was applied, with artificial lighting complementing natural lighting.

\section{Experimental design}

The birds were distributed in a completely randomized experimental design with a $3 \times 2$ (PABM inclusion $\times$ strain) factorial arrangement. The PABM was included at 0,50 and $100 \%$ ) and two strains (Amberlink and Hyline). Each treatment combination had seven replicates. Feed and water were provided ad libitum. The feeding experiment lasted 30 days, which was deemed long enough to assess the extent to which vitamins from the diet can be assimilated into eggs (Liu et al., 2012).

\section{Feed ingredients and experimental diets}

High Vitamin A maize variety (provitamin A-biofortified maize) was cultivated in Makhathini research station. White maize was also obtained from the same research station. Regular white maize was replaced with 0, 50 and $100 \%$ PABM. The ingredient composition of the experimental diets is shown in Table 1. Feed samples were analysed at Cedara College of Agriculture, Pietermaritzburg, South Africa. Analyses of the experimental formulated diets were carried out according to the procedures of Association of Official Analytical Chemists (A.O.A.C 1995). Crude protein was calculated as nitrogen content $\times 6.25$. Metabolizable energy (ME) was determined based on the proximate composition using the prediction equation outlined by Balogun and Olatidoye (2012). The diets were formulated to have similar crude protein and metabolizable energy levels.

\section{Measurements and data collection}

\section{Feed intake and changes on body weight}

The experimental birds were individually weighed every seven days. Feed intake was determined as the difference between the quantity of feed offered and the quantity of feed remaining in the feed trough and the spillages at the end of the week. The average daily feed intake (ADFI) was estimated by dividing the amount of feed consumed by 7 . The remaining feed in the feeding trough was then cleaned and refilled.

\section{Egg production}

Eggs were collected once a day. Egg weight measurements were taken every day throughout the experimental period. Eggs were weighed to the nearest $0.01 \mathrm{~g}$ using an electronic digital balance. Egg productivity for each treatment was estimated by dividing the total number of eggs produced during the experimental days by the number of birds multiplied by 100. Feed intake per kg egg mass for each treatment was computed by dividing total feed intake by total egg mass multiplied by 100 . 


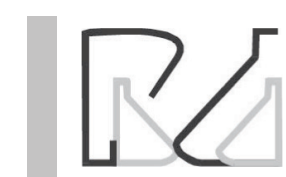

Table 1 - Percentage and calculated composition of the experimental diets (as is)

\begin{tabular}{lccc}
\hline Ingredient & \multicolumn{3}{c}{ PABM proportion (g/kg) } \\
\cline { 2 - 4 } & 0 & 500 & 1000 \\
\hline Pro-vitamin A bio-fortified maize & 0 & 315 & 630 \\
White maize & 630 & 315 & 0 \\
Soya bean meal 45\% & 240 & 235 & 229 \\
Vegetable oil & 31 & 36 & 42 \\
\hline Limestone & 51.5 & 51.5 & 51.5 \\
\hline Dicalcium phosphate & 11.8 & 11.8 & 11.8 \\
Salt & 3.0 & 3.0 & 3.0 \\
DL-Methionine & 3.4 & 3.4 & 3.4 \\
L-Lysine & 8.3 & 8.3 & 8.3 \\
Linoleic acid & 16 & 16 & 16 \\
Vit.-min. premix (excluding vit A) & 5 & 5 & 5 \\
Chemical composition & & & \\
Crude protein (g/kg) & 219 & 225 & 223 \\
Metabolizable energy, MJ kg-1 & 12.8 & 12.9 & 12.9 \\
\hline Ash (g/kg) & 91 & 85 & 97 \\
\hline Fat (g/kg) & 35 & 36 & 35 \\
\hline ADF (g/kg) & 53 & 34 & 42 \\
\hline NDF (g/kg) & 98 & 112 & 110 \\
\hline
\end{tabular}

\section{Egg shell quality}

A total of 516 (172 eggs for each dietary treatment and 258 eggs for each strain) eggs were collected and assessed for egg shell quality traits. The shell weight with intact membrane was obtained using an electronic balance. The thickness $(\mathrm{mm})$ of the shell with intact membranes was measured at the broad, sharp and middle part of the egg, by using digital callipers. The length and width of each egg were individually estimated using callipers. The egg shape index was calculated by dividing the width by the length of the egg, expressed as a percentage (Carter 1968).

\section{Egg albumen quality}

A total of 516 eggs (172 eggs for each dietary treatment and 258 eggs for each strain) were collected and individually weighed to the nearest $0.01 \mathrm{~g}$ using an electronic digital balance. After weighing, the eggs were broken out onto a plain glass for further egg quality measurements. An electronic height gauge was used to measure albumen height. The micrometre placement was approximately $6 \mathrm{~mm}$ from the yolk and the edge of the thick albumen. Albumen width was determined by averaging the minimum and maximum of the broken-out egg with a calliper. The reading for the albumen height was then used to calculate Haugh units as:

$\mathrm{HU}=100 \log (\mathrm{H}+7.57-1.7 \mathrm{~W}$ *0.37); where: $\mathrm{H}$ = albumen height $(\mathrm{mm}), \mathrm{W}=$ egg weight $(\mathrm{g}), 7.57$ = correction factor for albumen height, and $1.7=$ correction factor for egg weight (Haugh, 1937).
Nutritional Quality of Eggs of Amberlink and Hyline Layers Fed on Different Levels of Provitamin A-Biofortified Maize

The albumen index was defined as height of the albumen divided by the width of the albumen.

\section{Egg yolk quality}

The eggs were broken open in a plane plate and the albumen was separated from the egg yolk using an egg yolk separator. Separation of egg yolk from albumen was completed with a small strainer and a spatula. Then the egg yolk was gently rolled on tower paper to get rid of the remaining albumen. Consequently, egg yolk was weighed to the nearest $0.01 \mathrm{~g}$. Measurement of height and width of the yolk was done using a calliper. The yolk index was determined by dividing the height of the yolk by its width, Funk, 1948. For the egg yolk quality parameters 516 yolk samples were measured.

At the end of the trial, egg yolk colour differences were measured using a chromameter (Model CR300; Minolta Camera Co. Ltd., Osaka Japan). The chromameter was standardized using both a white and black plate. Colour was measured based on lightness $(L)$, amount of red $\left(a^{*}\right)$ and amount of yellow $\left(b^{*}\right)$.

\section{Determination of Vitamin A content in egg yolk}

Egg yolk samples were collected on Day 0, 15 and 30. Eggs from each replicate were collected and the yolk was separated from the albumen using the same procedure as for the egg yolk colour analyses. From each replicate, $10 \mathrm{ml}$ of egg yolk was collected and mixed thoroughly to make a homogenous mixture. The samples were stored in a deep freezer until they were ready for vitamin A analysis. A $0.2 \mathrm{~g}$ of each egg yolk was placed in a $10-\mathrm{mL}$ pyrex glass vial and mixed with $1 \mathrm{ml}$ of distilled water, $2 \mathrm{~mL}$ of $1000 \mathrm{~mL} \mathrm{~L}^{-1}$ ethanol and $10 \mathrm{~mL} \mathrm{~L}^{-1}$ butylated hydroxytoluene (BHT) was added. Then $0.5 \mathrm{~mL}$ of saturated $\mathrm{KOH}$ was added to the mixture and mixing for another 10s. This mixture was heated for $1 \mathrm{~h}$ at $60{ }^{\circ} \mathrm{C}$ to saponify the lipids and hydrolysed the carotenol esters. The saponified egg yolk samples were extracted and analysed using high performance liquid chromatography (HPLC) for carotenoid content.

\section{Statistical analyses}

Data were analyzed using general linear model procedure of SAS (version 9.3) with the main effects being the strain of hen and PABM inclusion. Statistical significance were based on $p<0.05$. After checking the data for normality using PROC UNIVARIATE, all data were normally distributed and the variances were homogenous. The model used was:

$$
Y_{i j k k}=\mu+W_{i}+P_{j}+S_{k}+(W \times P)_{i j}+(P \times S)_{j k}+(W \times S)_{i k}+
$$
$(P \times W \times S)_{i j k}+e_{i j k l}$ Where: 

$\mu=$ overall mean common to all observations
$W_{i}=$ week effect $(i=1,2,3,4)$
$P_{j}=\operatorname{PABM}$ inclusion $(j=1,2,3)$
$S_{k}=\operatorname{Strain}(k=1,2)$
$(\mathrm{W} \times \mathrm{P})_{\mathrm{ij}}=$ Interaction between week and diet
$(P \times S)_{j k}=$ Interaction between diet and strain
$(\mathrm{W} \times \mathrm{S})_{\mathrm{ik}}=$ Interaction between week and strain
$(\mathrm{P} \times \mathrm{W} \times \mathrm{S})_{\mathrm{ijk}}=$ Interaction between week, dietand strain
$\mathrm{E}_{\mathrm{ijk} \mathrm{k}}=$ random residual error

\section{RESULTS}

\section{Feed intake and body weight changes}

Table 2 shows the body weights and daily feed intake for the Amberlink and Hyline layers. Experimental period had no significant effect on the body weight changes throughout the experiment. Birds fed on the $100 \%$ PABM diet had significantly lighter body weight. There was no diet $x$ strain interaction on body weight changes (Table 2). Amberlink birds receiving $50 \%$ PABM had the highest body weight, yet for Hyline layers, birds that received $100 \%$ PABM were the lightest. Strain and PABM inclusion significantly affected feed intake. There was also the PABM inclusion $x$ strain interaction on ADFI. In both strains, ADFI was higher $(p<0.05)$ for those birds that were on $50 \%$ PABM inclusion than either 0 or $100 \%$ inclusion. In both strains, birds that received the diet that contained $100 \%$ PABM had the lowest ADFI.

\section{Egg production, egg weight and feed intake per egg mass}

There was a significant strain $\times$ diet interaction on egg production $(p<0.05$; Table 2$)$. Hyline birds fed on the diet containing $50 \%$ PABM had significantly low percentage of egg production. For Amberlink birds, egg production percentage was highest for the birds that received 50 \% PABM. Hyline birds that received 100 $\%$ PABM, however, had the highest egg production. Hyline birds on $50 \%$ PABM had 30 percentage points lower than Amberlink birds on the same PABM inclusion level. Hyline birds needed more feed $(p<0.05)$ to produce a gram of egg than Amberlink birds. Hyline eggs were significantly heavier than Amberlink eggs. Within each strain, PABM inclusion did not influence egg weight ( $p>0.05)$.

\section{Effect of strain and diet on egg shell quality}

Table 3 shows the least square means and standard error of egg shell weight and egg shell percentage for both Amberlink and Hyline birds. Strain and diet had significant effect on egg shell weight. Eggs from hens that received $100 \%$ PABM had lighter egg shells than those on lower PABM levels. Eggs produced by layers under $100 \%$ PABM diet had significantly inferior eggshell quality traits. Both strain and PABM inclusion did not affect egg shell thickness. The egg shell percentage was significantly affected by both strain and PABM inclusion.

\section{Effects of strain and diet on albumen quality}

The effect of PABM inclusion and strain on albumen quality characteristics of eggs is shown in Table 3 . Strain and PABM inclusion had no effects on albumen height. Albumen diameter was significantly affected by strain and PABM inclusion. Inclusion of PABM had no effect on albumen index, but strain did. Amberlink eggs had higher $(p<0.05)$ albumen index than Hyline eggs. Albumen weight was affected $(p<0.05)$ by

Table 2 - Effect of strain and inclusion of provitamin A-biofortified maize (PABM) on body weight, average daily feed intake (ADFI), egg production (\%) and feed intake per egg weight

\begin{tabular}{|c|c|c|c|c|c|c|c|c|}
\hline \multirow{2}{*}{ Parameters } & \multirow[t]{2}{*}{ Strain } & \multicolumn{3}{|c|}{ PABM inclusion (\%) } & \multirow[t]{2}{*}{ SEM } & \multicolumn{3}{|c|}{$P$ value } \\
\hline & & 0 & 50 & 100 & & $\mathrm{~S}$ & D & $S \times D$ \\
\hline \multirow[t]{2}{*}{ Body weight (kg) } & Amberlink & $1.74^{a}$ & $1.78^{b}$ & $1.73^{a}$ & 0.027 & 0.00 & 0.04 & 0.37 \\
\hline & Hyline & $1.93^{d}$ & $1.92^{d}$ & $1.84^{c}$ & & & & \\
\hline \multirow[t]{2}{*}{ ADFI (g/day) } & Amberlink & $90.5^{\mathrm{ab}}$ & $93.9^{b}$ & $85.6^{a}$ & 2.82 & 0.00 & 0.00 & 0.01 \\
\hline & Hyline & $103.7^{c}$ & $110.7^{d}$ & $86.1^{\mathrm{a}}$ & & & & \\
\hline \multirow[t]{2}{*}{ Egg production (\%) } & Amberlink & $88.8^{b c}$ & $92.4^{c}$ & $84.7^{b}$ & 5.45 & 0.00 & 0.44 & 0.04 \\
\hline & Hyline & $77.6^{b}$ & $61.7^{a}$ & $81.1^{b}$ & & & & \\
\hline \multirow[t]{2}{*}{ Egg weight (g) } & Amberlink & $51.2^{\mathrm{a}}$ & $52.9^{a}$ & $50.4^{a}$ & 0.24 & 0.00 & 0.19 & 0.00 \\
\hline & Hyline & $55.4^{b}$ & $54.8^{b}$ & $53.9^{b}$ & & & & \\
\hline \multirow[t]{2}{*}{ Feed intake per egg mass } & Amberlink & $2.0^{a}$ & $1.8^{\mathrm{a}}$ & $1.9^{a}$ & 0.17 & 0.00 & 0.15 & 0.30 \\
\hline & Hyline & $2.5^{b}$ & $2.5^{b}$ & $2.0^{b}$ & & & & \\
\hline
\end{tabular}

SEM: standard error of mean

S: strain; D: PABM inclusion level; S×D: strain $\times$ PABM inclusion interaction 
Table 3 - Eggshell and albumen quality of Amberlink and Hyline hens fed on provitamin A-biofortified maize (PABM)

\begin{tabular}{|c|c|c|c|c|c|c|c|c|}
\hline \multirow[t]{2}{*}{ Component } & \multirow[t]{2}{*}{ Strain } & \multicolumn{3}{|c|}{ PABM (\%) } & \multicolumn{4}{|c|}{$p$ values } \\
\hline & & 0 & 50 & 100 & SEM & $S$ & $D$ & $S \times D$ \\
\hline \multirow[t]{2}{*}{ ESW (g) } & Amberlink & $4.3^{b}$ & $4.5^{c}$ & $4.1^{\mathrm{a}}$ & 0.06 & 0.021 & 0.04 & 0.712 \\
\hline & Hyline & $4.8^{d}$ & $4.8^{d}$ & $4.4^{b}$ & & & & \\
\hline \multirow[t]{2}{*}{ EST (mm) } & Amberlink & 0.306 & 0.315 & 0.302 & 0.03 & 0.181 & 0.420 & 0.267 \\
\hline & Hyline & 0.315 & 0.333 & 0.310 & & & & \\
\hline \multirow[t]{2}{*}{ Eggshell \% } & Amberlink & $8.42^{\mathrm{ab}}$ & $8.47^{\mathrm{ab}}$ & $8.22^{\mathrm{a}}$ & 0.11 & 0.035 & 0.210 & 0.363 \\
\hline & Hyline & $8.56^{b}$ & $8.91^{b}$ & $8.17^{a}$ & & & & \\
\hline \multirow[t]{2}{*}{ Albumen height } & Amberlink & 6.16 & 6.17 & 5.96 & 0.08 & 0.254 & 0.123 & 0.658 \\
\hline & Hyline & 5.96 & 6.03 & 6.12 & & & & \\
\hline \multirow[t]{2}{*}{ Albumen diameter } & Amberlink & $68.0^{a}$ & $71.5^{b}$ & $68.6^{a}$ & 0.63 & 0.041 & 0.230 & 0.684 \\
\hline & Hyline & $78.5^{d}$ & $77.4^{d}$ & $76.3^{c}$ & & & & \\
\hline \multirow[t]{2}{*}{ Albumen index } & Amberlink & $9.1^{\dagger}$ & $8.7^{d}$ & $8.9^{e}$ & 0.14 & 0.022 & 0.361 & 0.043 \\
\hline & Hyline & $7.6^{a}$ & $7.9^{b}$ & $8.1^{c}$ & & & & \\
\hline \multirow[t]{2}{*}{ Albumen weight } & Amberlink & $33.25^{\mathrm{a}}$ & $35.40^{b}$ & $32.57^{a}$ & 0.37 & 0.048 & 0.418 & 0.322 \\
\hline & Hyline & $36.66^{c}$ & $35.42^{b}$ & $36.04^{b c}$ & & & & \\
\hline \multirow[t]{2}{*}{ Haugh unit } & Amberlink & $80.7^{b}$ & $80.1^{\mathrm{b}}$ & $80.2^{\mathrm{ab}}$ & 0.53 & 0.033 & 0.730 & 0.554 \\
\hline & Hyline & $77.5^{\mathrm{a}}$ & $78.4^{\mathrm{ab}}$ & $79.0^{\mathrm{ab}}$ & & & & \\
\hline
\end{tabular}

ESW: Egg shell weight; EST: egg shell thickness; SEM: standard error of mean.

S: strain; D: PABM inclusion level; S×D: strain $\times$ PABM inclusion interaction.

strain and PABM inclusion. The interaction was not significant. Eggs from hens that were consuming diets the contained PABM had the highest albumen weight. Only strain affected $\mathrm{HU}$, with the Amberlink eggs having a higher $(p<0.05) \mathrm{HU}$ than Hyline birds.

\section{Effects of strain and diet on egg yolk quality}

The influence of PABM inclusion on colour $\left(L^{*}, a^{*}\right)$ of egg yolks are shown in Table 4, while $b^{*}$ values are illustrated in Figure 1. Inclusion level of PABM had significant effect on the $L^{*}, a^{*}, b^{*}$ values. As the level of PABM increased, the yellow and red hue (Hunter $a *$ and $b$ * values) significantly increased while the lightness values (Hunter $L^{*}$ values) decreased. Strain of birds had no significant effect on the colour of the egg yolk. Inclusion of PABM in the diet had no significant effect on yolk height, yolk diameter and yolk index. Yolk weight was higher $(p<0.05)$ in Hyline than Amberlink eggs (Table 4).

\section{Effects of strain and diet on Vitamin A composition of egg yolk}

Table 5 shows the effect of strain and diet on the assimilation of vitamin A from the diet to the egg yolk. There was a significant period effect on Vitamin A content in egg yolks for both chicken strains. For both

Table 4 - Effect of strain and inclusion of provitamin A biofortified maize (PABM) on egg yolk quality and colour

\begin{tabular}{|c|c|c|c|c|c|c|c|c|}
\hline \multirow[t]{2}{*}{ Yolk quality } & \multirow[t]{2}{*}{ Strain } & \multicolumn{3}{|c|}{ PABM inclusion } & \multirow[b]{2}{*}{ SEM } & \multicolumn{3}{|c|}{$P$ values } \\
\hline & & 0 & 50 & 100 & & $\mathrm{~s}$ & D & $S \times D$ \\
\hline \multirow[t]{2}{*}{$L^{*}$} & Amberlink & $73.4^{c}$ & $68.6^{b}$ & $65.4^{\mathrm{a}}$ & 0.51 & 0.107 & 0.000 & 0.703 \\
\hline & Hyline & $73.7^{c}$ & $69.8^{b}$ & $66.1^{\mathrm{a}}$ & & & & \\
\hline \multirow[t]{2}{*}{$a^{*}$} & Amberlink & $-2.5^{a}$ & $5.6^{b}$ & $11.0^{c}$ & 0.50 & 0.145 & 0.000 & 0.551 \\
\hline & Hyline & $-2.5^{\mathrm{a}}$ & $4.8^{b}$ & $10.4^{c}$ & & & & \\
\hline \multirow[t]{2}{*}{ Yolk height } & Amberlink & $15.7^{\mathrm{a}}$ & $15.7^{\mathrm{a}}$ & $15.8^{\mathrm{a}}$ & 0.16 & 0.006 & 0.152 & 0.468 \\
\hline & Hyline & $15.9^{a}$ & $15.9^{\mathrm{a}}$ & $16.3^{b}$ & & & & \\
\hline \multirow[t]{2}{*}{ Yolk diameter } & Amberlink & 36.8 & 36.9 & 37.1 & 0.27 & 0.100 & 0.44 & 0.791 \\
\hline & Hyline & 37.5 & 37.9 & 37.8 & & & & \\
\hline \multirow[t]{2}{*}{ Yolk index } & Amberlink & 0.43 & 0.43 & 0.43 & 0.59 & 0.376 & 0.164 & 0.129 \\
\hline & Hyline & 0.42 & 0.42 & 0.43 & & & & \\
\hline \multirow[t]{2}{*}{ Yolk weight } & Amberlink & $13.9^{\mathrm{a}}$ & $13.7^{a}$ & $13.9^{\mathrm{a}}$ & 0.13 & 0.200 & 0.689 & 0.669 \\
\hline & Hyline & $14.6^{\mathrm{b}}$ & $14.6^{b}$ & $14.5^{\mathrm{b}}$ & & & & \\
\hline
\end{tabular}

S: strain; D: PABM inclusion level; S×D: strain $\times$ PABM inclusion interaction. 


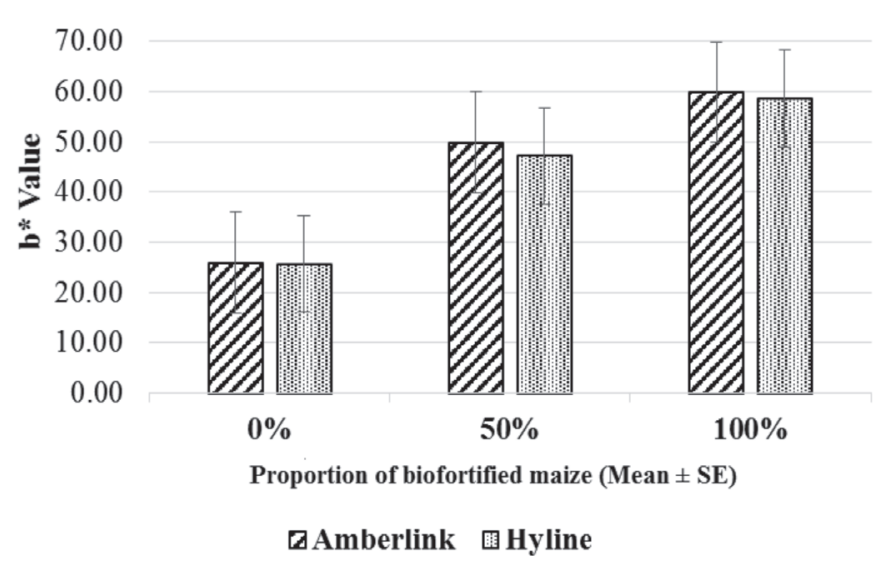

Figure 1 - Influence of inclusion of provitamin A biofortfied maize (PABM) on yellowness ( $b$ * value) of Amberlink and Hyline egg yolks

Hyline and Amberlink eggs, vitamin A concentration was higher in eggs collected after 15 days of exposure to the PABM as compared to those at the beginning of the trial. Similarly, the vitamin A content was higher on Day 30 than on Day 15. At all three periods of Vitamin A content determination, no strain effect on vitamin A in egg yolks was observed. In both strains, eggs from chickens that were fed on $50 \%$ PABM were similar between day 15 and 30. Eggs from chickens that were fed on $100 \%$ PABM were, however, higher for day 30 than on day 15 .

\section{DISCUSSION}

The need to curb VAD among resource-limited households has led to scientists proposing the use of biofortification of agricultural products, such as maize (Howe \& Tanumihardjo 2006; De Groote \& Kimenju 2008). One of the goals of bio-fortification is to reduce VAD by improving the micronutrient density of the staple food crops that are produced and consumed by low-income populations. Hence, the main target beneficiaries of provitamin A-biofortified crops are resource-poor households whose diets highly depend on staples with low nutritional quality and who have a limited access to other vitamin A-rich foods. Biofortified maizeis are a more accessible source of bioavailable provitamin A than other sources of retinol or provitamin A carotenoids (Tanumihardjo et al., 2010). Biofortification of maize, however, reduces its acceptability by consumers (Stevens 2008).

It is well recognised that feeding feeds with high carotene levels to chickens increases the Vitamin A content of eggs. The response in the Vitamin A content in eggs depends on factors such as the genotype of the bird being fed, exposure of the feed to sunlight, concentration and type of carotenes on the feed and the length of time that chickens are exposed to the biofortified feed (Liu et al., 2012). The study was, therefore, designed to explore assimilation of Vitamin A in eggs from Amberlink and Hyline birds to incremental levels of PABM in the feed.

The observation that, for both strains, birds that were fed on the diet containing $100 \%$ PABM had lower feed intake than those on the other diets was not expected. It is possible that the birds could meet their nutritional requirements earlier when fed on 100 $\%$ PABM than on white maize. There is, however, a need to identify nutritional differences among the maize varieties. The influence of high concentrations of $\beta$-carotene on appetite and bioavailability of other nutrients is still unclear. Determining the optimum PABM inclusion in diets of laying birds, therefore, requires further investigation. A dose-response trial could be designed to identify the optimum PABM inclusion level without compromising the performance of layers.

Feed consumption is a variable phenomenon and is influenced by several factors such as strain of the bird and nutrient content of the diet. Feed intake is primarily influenced by the energy level of the diet. Pillay et al., (2013) reported that PABM have superior level of starch and crude protein as compared to white maize. The low

Table 5 - Effect of strain and inclusion of provitamin A biofortified maize (PABM) on vitamin A content of egg yolks $(\mathrm{mg} / 100 \mathrm{~g})$

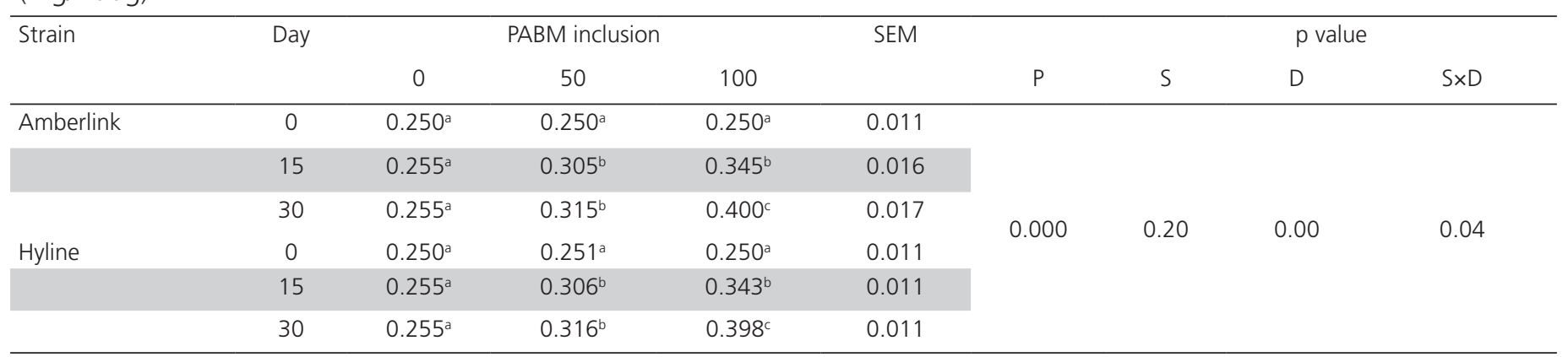

P: experimental period; S: strain; D: PABM inclusion level; S×D: strain $\times$ PABM inclusion interaction. 
feed intake in birds fed on $100 \%$ PABM could have a negative effect on the consumption of other essential nutrients. For example, if the optimal calcium and phosphorus requirements are not met due to low feed intake, the quality of egg shells could be compromised. The interaction between strain and PABM inclusion on ADFI was also unexpected. For Amberlink birds, the feed intake dropped by $5 \%$, while a massive 17\% drop was observed for the large-framed Hyline layers. These findings suggest that inclusion of PABM to curb VAD should take into account the strain of bird to be utilised.

Egg weight is one of the important traits that influence consumer's egg purchasing behaviour. One of the main factors influencing egg size is body size of the laying chicken (Robinson \& Sheridan, 1982; Summer \& Leeson, 1983). As expected, the egg weight for the Hyline birds was significantly heavier than that of Amberlink birds. Lacin et al., (2008) also explained the negative relationship that exists between egg weight and egg production. Increase in body weight decreases egg production, while egg weight and feed consumption increase. Heavy birds consume more feed and lay larger egg with large egg yolk than light hens. Even though, inclusion of PABM had no direct effect on egg weights and egg production, strain of the bird and the strain $\times$ PABM inclusion interaction had significant effect on egg weights and egg production. Moreover, the recommended value of FCR for Hy-line layers for the age range of 20 to 90 weeks is 1.95 to 2.07. The observation that, the Hy-line birds except for those on the diet containing $100 \%$ PABM, had high value of FCR than the recommended was not expected. It was however, expected that layers with heavier body weight would produce fewer eggs. It is possible that, the high level of FCR of those Hy-line layers on the diets $0 \%$ and $50 \%$ of PABM could be caused by their significantly heavy body weight as comparing to the Hy-line layers under $100 \%$ PABM diet.

Both strain and PABM inclusion affected egg shell quality. Khurshid et al., (2003) reported that egg weight is positively related to egg shell weight and thickness. It was, therefore, expected that Hyline eggs would have thicker and heavier egg shells. Strain of bird on egg shell thickness was, however, not significant. Eggs produced by layers fed on $100 \%$ PABM had thinner egg shell thickness and lighter weight than those on the other diets. Birds on $50 \%$ PABM diet had the strongest egg shells. These findings suggest that when developing technologies to increase Vitamin A content in eggs, the egg shell quality is of economic importance. For table eggs, the egg shell functions as a packaging material and its good quality is crucial to consumer selection and safety. Therefore, any intervention that is intended to improve the internal quality of eggs should not compromise the quality of the egg shell.

Storage environmental conditions also affect albumen quality. Earlier reports (e.g. Williams, 1992; Lewko \& Gornowicz, 2010) show significant effect of strain on albumen quality. Albumen diameter, index and weight all differed with strain. Inclusion of PABM had no marked influence on albumen characteristics.

Yolk colour plays a very important role on consumer perception of eggs (Galobart et al., 2004). In other words, the colour of the egg yolk directly affects the sensory acceptability of eggs. Hence it has been the subject of scientific studies for many years. Yolk color fan and digital colorimeter measurements are currently commonly used in the determination of the yellow color of eggs. For this study, the measurements were done by using Chromameter. The result of the current study depicts that, yolk colour shows a darker, redder and more yellow as the PABM level in the diet increased. Redness of the yolk increased more than three times between the control diet and $50 \%$ PABM and again doubled as the level of PABM increased to $100 \%$. Visually, this means a shift towards a more orange colour. Strain of layers had no any effect on the colour of the egg yolk, therefore, all the difference were merely due to the dietary effect. For it's simplicity to obtain result and because it is inexpensive method, many researchers today have been using the Roche yolk color fan grades to measure the egg yolk color. Narinc et al., (2015), demonstrated the relationship between the two Roche egg yolk color fan and the digital colorimeter. They found out that the compatibility of Roche yolk color fan grades with $L^{*}$, $a^{*}, b^{*}$ values measured with the help of a device to be $90.12 \%, 99.14 \%, 38.82 \%$, respectively $(p<0.01$ for all three). When the results of the current study intercepted with the findings of Narinc et al., (2015), for the $L$ (lightness) values which were $73.55,69.2$ and 65.75 corresponded to the 11 th 13 th and 15 th of the Roche egg yolk color fan value for diets containing 0 , 50 and $100 \%$ of PABM respectively. The results for $a^{*}$ value (redness) were $-2.5,5.2$ and 10.7 for diets containing 0,50 and $100 \%$ of PABM respectively. When corresponded to the Roche egg yolk color value by adopting Narinc et al., (2015) result, it fall under the $3 \mathrm{rd}, 6$ th and 10 th value of the fan reading. Since the results of Narinc et al., (2015) illustrate that there was low compatibility between the Roche egg yolk color and $b$ * value of the device reading we omit to intercept 
our result to Roche egg yolk color value. In conclusion, using PABM in layers feed significantly affected the colour of the egg yolk. So it is imperative to assess consumer acceptability of these eggs by target groups before drawing up recommendations.

The observed effect of strain on the height, diameter, index and weight of egg yolks were expected. Egg yolk weight is directly correlated with the size of eggs. Vitamin A concentrations in their egg yolks were similar between the two strains. The vitamin A concentration increased at Day 15 and further increased at Day 30. Our findings agree with Liu et al., (2012) who reported that birds are able to extract the carotene in maize and form Vitamin A in eggs. Birds fed on diets containing $100 \%$ PABM had higher concentrations of Vitamin A than those on $50 \%$ PABM. These findings suggest that inclusion levels of PABM may be limited by factors such as egg shell quality. Although strain differences were not detected in the current study, it is highly likely that chickens that are adapted to grazing and browsing are likely to have a larger capacity to convert beta carotene in to Vitamin A.

\section{CONCLUSIONS}

Both the inclusion of PABM affected feed intake but not egg weight and egg productivity. Strain and PABM inclusion affected egg shell quality. Hens that were fed on diets containing $100 \%$ PABM produced eggs with lower egg shell weight. Strain had no effect on the colour of egg yolk. As the level of PABM in the layers feed increased, however, the yellowness and redness of egg yolk increased while the lightness decreased. Vitamin A content of egg yolk increased as the level of PABM in the diet increased.

\section{REFERENCES}

AOAC - Association of Official Methods of Analysis. Official methods of analysis of AOAC international. 16th ed. Gaithersburg ;1995.

Balogun IO, Olatidoye OP. Chemical composition and nutritional Evaluation of velvet bean seeds (Mucuna utilis) for Domestic consumption and industrial utilization in Nigeria. Pakistan Journal of Nutrition 2012;11:116

Carter TC. The hen's egg: a mathematical model with three parameters. British Poultry Science 1968;9:165-171.

De Groote H, Kimenju SC. Comparing consumer preferences for color and nutritional quality in maize: Application of a semi-double-bound logistic model on urban consumers in Kenya. Food Policy 2008;33:362-370.
Funk EM. The relation of the yolk index determined in natural position to the yolk index as determined after separating the yolk from the albumen. Poultry Science 1948;27:367.

Galobart J, Sala R, Rincón-Carruyo X, Manzanilla EG, Vila B, Gasa J. Egg yolk color as affected by saponification of different natural pigmenting sources. The Journal of Applied Poultry Research 2004;13:328-334.

Haugh RR. The haugh unit for measuring egg quality. United States Egg and Poultry Magazine 1937;43:552-555

Howe JA, Tanumihardjo SA. Carotenoid-biofortified maize maintains adequate vitamin A status in Mongolian gerbils. The Journal of Nutrition 2006;136:2562-2567.

Khurshid A, Farooq M, Durrani FR, Sarbiland K, Chand N. Predicting egg weight, shell weight, shell thickness and hatching chick weight of Japanese quails using various egg traits as regressors. International Journal of Poultry Science 2003;2:164-167.

Lacin E, Yildiz A, Esenbuga N, Macit M. Effects of differences in the initial body weight of groups on laying performance and egg quality parameters of Lohmann laying hens. Czech Journal Animal Science 2008;53:466-471.

Lewko L, Gornowicz E. Egg albumen quality as affected by bird origin. Journal of Central European Agriculture 2010;10:455-463.

Liu YQ, Davis CR, Schmaelzle ST, Rocheford T, Cook ME, Tanumihardjo SA. $\beta$-Cryptoxanthin biofortified maize (Zea mays) increases $\beta$-cryptoxanthin concentration and enhances the colour of chicken egg yolk. Poultry Science 2012;91:432-438.

Naber E, Squires M. Vitamin profiles of eggs as indicators of nutritional status in the laying hen: Diet to egg transfer and commercial flock survey. Poultry Science 1993;72:1046-1053.

Narinç D, Aygün A, Küçükönder H, Aksoy T, Gürcan EK. An application of bootstrap technique in animal science: egg yolk color sample. Kafkas Üniversitesi Veteriner Fakültesi Dergisi 2015;21:631-637.

Pillay K, Siwela M, Derera J, Veldman FJ. Influence of biofortification with provitamin A on protein, selected micronutrient composition and grain quality of maize. African Journal of Biotechnology 2013;12:52855293

Robinson D, Sheridan AK. Effects of restricted feeding in growing and laying period on the performance of White Leghorn by Australorp cross-bred and White Leghorn strain cross chickens. British Poultry Science 1982;23:199-214.

Stevens R. Prospects for using marker-assisted breeding to improve maize production in Africa. Journal of Science, Food and Agriculture 2008;88:745-755

Summer JD, Leeson S. Factors influencing egg size. Poultry Science $1983 ; 62: 1155-1159$.

Tanumihardjo SA, Palacios N, Pixley KV. Provitamin A carotenoid bioavailability: what really matters? International Journal for Vitamin and Nutrition Research 2010;80:336-350.

Williams KC. Some factors affecting albumen quality with particular reference to Haugh unit score. World's Poultry Science Journal 1992;48:5-16 